\title{
A Case of Cutaneous T-Cell Lymphoma with Nodular Skin Lesions, Third Nerve Palsy and Peripheral Vascular Disease: Can It Be a Case of Angiocentric Lymphoma?
}

\author{
Rahaman MFU ${ }^{\mathrm{a}}$, Chowdhury $\mathrm{MMH}^{\mathrm{b}}$, Bhuiyan $\mathrm{AKMMR}^{\mathrm{c}}$, Chowdhury MAJ ${ }^{\mathrm{d}}$
}

\begin{abstract}
Angiocentric lymphoma is a subtype of cutaneous T-cell lymphoma, characterized by occlusion of vessels by lymphoid infiltrate. Here, we report a case of biopsy confirmed cutaneous T-cell lymphoma who presented with third cranial nerve palsy, peripheral vascular disease and nodular skin lesions in the right thigh. All these findings of this case can be explained by mechanism of vascular infiltration and tissue destruction in angiocentric lymphoma which is a rare disorder.
\end{abstract}

Key word: Angiocentric lymphoma, Cutaneous T-cell lymphoma, Nodular skin lesion, Peripheral vascular disease, Third cranial nerve palsy.

Birdem Med J 2016; 6(1): 40-42

\section{Introduction}

Cutaneous T-cell lymphoma (CTCL) is a rare disease with an incidence of 4.2 cases per million populations and usually develops slowly over many years in patients older than 50 years. ${ }^{1}$ At initial presentation, the disease is usually limited to the skin with lesions that resemble eczema or psoriasis followed by development of nodular skin swelling with involvement of lymphnodes in advanced stage. Finally, visceral involvement occurs. Involvement of central nervous system (CNS) is observed in $1.6 \%$ cases withCTCL. ${ }^{2}$ Though autopsy quoted higher rate (10\%), clinical manifestations are less

\section{Author Information}

a. Dr. Mohammad Ferdous Ur Rahaman, MBBS, FCPS (Medicine), Assistant Professor, Department of Internal Medicine, BSMMU.

b. Dr. Mohammad Mainul Hasan Chowdhury, MBBS, MD (Internal Medicine), Former Resident of Internal Medicine, BSMMU.

c. Dr. AKM Motiur Rahman Bhuiyan, MBBS, MD (Internal Medicine), Associate Professor, Department of Internal Medicine, BSMMU.

d. Prof. MA Jalil Chowdhury, MBBS, FCPS, MD, FACP, Professor of Internal Medicine, BSMMU.

Address of correspondence: Dr. Mohammad Ferdous Ur Rahaman, MBBS, FCPS (Medicine), Assistant Professor, Department of Internal Medicine, BSMMU, Email: ferdous bsmmu@yahoo.com

Received: April 3, 2015

Accepted: November 30, 2015 frequent. ${ }^{3}$ Angiocentric lymphoma (AL) is a subtype of CTCL which is characterized by occlusion of vessels by lymphoidinfiltrate. Clinical manifestation of AL widely varies because of different organ involvement by diffuse vascular infiltration and CNS manifestation is not uncommon. Proper diagnosis of AL is important for choice of specific therapy, as treatment widely varies among different varieties of CTCL with variable outcome. Here, we report a case of CTCL with strong suspicion of AL who presented with third nerve palsy, peripheral vascular disease, nodular skin lesions and soft tissue swelling.

\section{Case report}

A 72-year-old Bangladeshi man presented with progressive development of multiple nodular skin lesions over eight months involving his right inguinal region, right thigh (Figure 1) and both axilla. The patient also developed progressive painless swelling of his right thigh and right leg over six months (Figure 1) and drooping of the left upper eye lid for two weeks. He was diagnosed as a case of diabetes mellitus (DM) six months back and was on good glycemic control with gliclazide. He was smoker and was getting management of chronic obstructive pulmonary disease for three years. 


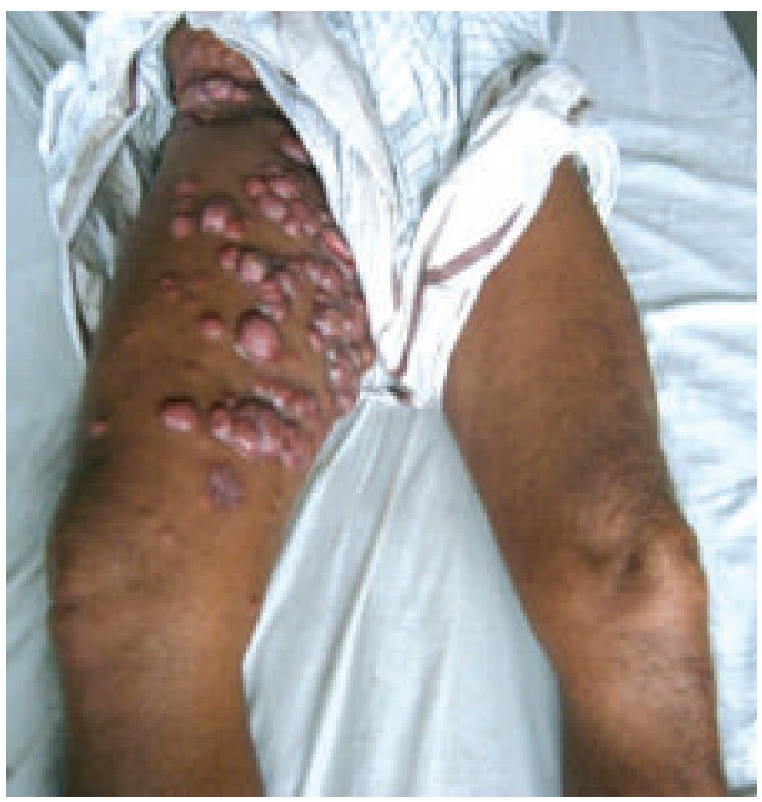

Figure-1: Nodular skin lesion and soft tissue swelling over right thigh

On examination, swellings were variable in size and shape, itchy, erythematous, some were tender and some were ulcerated. There was left third cranial nerve palsy with partial ptosis, divergent squint and dilated pupil. Accommodation and light reflexes were absent with visual impairment of the left eye. There was no other focal neurological sign.

Patient had high erythrocyte sedimentation rate $(80 \mathrm{~mm}$

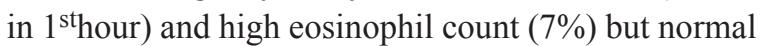
haemoglobin $(11 \mathrm{~g} / \mathrm{dl})$, white blood cell $(7,000 / \mathrm{cmm}$ of blood) and platelet $(3,00,000 / \mathrm{cmm}$ of blood). Chest Xray and abdominal ultrasonogram revealed no abnormality except enlarged prostate with increased post voidal residue $(62 \mathrm{ml})$. Serum creatinine $(1 \mathrm{mg} / \mathrm{dl})$, fasting blood glucose $(5.6 \mathrm{mmol} / \mathrm{L})$ and serum alanine aminotransferase $(18 \mathrm{U} / \mathrm{L})$ were normal but Serum lactate dehydrogenase was raised $(287 \mathrm{U} / \mathrm{L})$. Electrocardiogram (ECG) revealed antero-lateral ischaemia. Duplex study of lower limb vessels revealed mild reduction of blood flow in anterior tibial, posterior tibial and dorsalispedis arteries of both lower limbs with normal venous returns. Biopsy from the nodular lesion of skin revealed infiltration of atypical lymphoid cells in the reticular dermis that extended towards the superficial portion of dermis. The findings were compatible with cutaneous lymphoma. Immuno histopathology report was compatible with T-cell lymphoma as evidenced by presence of positive CD3 marker (CD4 Negative).

As a case of cutaneous T-cell lymphoma, treatment with methotrexate, psoralen ultraviolet-A (PUVA) and interferon therapy were started. Further evaluation by brain imaging, lumber puncture and angiography were planned but could not be done as the patient died suddenly without any established cause of death.

\section{Discussion}

Involvement of the CNS occurs within 3-5 years from initial diagnosis of CTCL with involvement of brain, meninges, brainstem alongwith advanced infiltration in other organs like lymph node and viscera. ${ }^{4-6}$ Chua et al. reported eighth cranial nerve deficits with deafness in a patient who had negative computed tomography (CT) scan and magnetic resonance imaging(MRI) but lymphomatousleptomeningeal disease in cerebro-spinal fluid (CSF). ${ }^{7}$ Changes in the brainstem were also demonstrated with MRI in CTCL patients with neurological symptomsin the absence of systemic visceral involvementelsewhere. ${ }^{8,9}$ Raquel del CarpioO'Donovan and Carolyn Freeman reported brainstem changes with MRI in a CTCL patient who had normal CSF findings. ${ }^{8}$ The lesions were not space-occupying and did not take any contrast. Atautopsy, they found that the lesions in the brainstem were consistent with ischemicchanges. ${ }^{8}$ Findings were related to the numerous vessels filled with cells that stained with Tcell markers. ${ }^{8}$ This features were identical to the occlusion of vessels by lymphoidinfiltrate described in $\mathrm{AL}$, the term used in the Revised European American Lymphoma (REAL) classification. ${ }^{10}$

The third cranial nerve palsy without any other focal neurological sign in our patient can be explained by ischemic changes without any space occupying lesion in the brainstem due to vascular infiltration by tumour cells rather than neoplastic invasion of the parenchyma in AL. Although third cranial nerve palsy can occur in $\mathrm{DM}$, involvement of pupil is uncommon as occurred in this patient.

Short duration of well controlled DM without any evidence of diabetic retinopathy (normal eye examination), diabetic nephropathy (no proteinuria) and diabetic neuropathy (no clinical symptoms and sign) made the vascular and neurological complications of DM less likely. As there was no history of hypertension, 
chronic angina or intermittent claudication, the changes in ECG and duplex imaging are less likely to be due to atherosclerosis. So, the widespread vascular involvement in duplex imaging of lower limb vessels and antero-lateral ischaemic changes in ECG can also be explained on the pathological basis of diffuse vascular involvement in AL.

Amongthe peripheral T-cell neoplasms, AL refers to processes that are localized in extranodal sites, infrequently the skin, these may occur for years prior to diagnosis. ${ }^{11}$ Asthe disease progresses, AL tendsto invade and destroy vessels, often resulting in coagulative necrosis. So, nodular skin lesion and soft tissue swelling of right lower limb in our patient can also be well explained by the local invasion mechanism of AL. Though complete evaluation could not be done and all the finding scan still be explained by DM and atherosclerosis related complications, AL should be a strong suspicion in the background of biopsy and immuno histopathology proven CTCL diagnosis.

In conclusion it can be said that ALis a rare entity, requires specific therapy and should be suspected in a case of CTCL who presents with cranial nerve palsy, vascular disease and skin lesions.

\section{Conflict of interest: None.}

\section{References}

1. Weinstock MA, Horm JW. Mycosis fungoides in the United States: increasing incidence and descriptive epidemiology. J Am Med Assoc1988; 260:42-46.
2. Kaufman DK, Habermann TM, Kurtin PJ, O’Neill BP. Neurological complications of peripheral and cutaneous T-cell lymphomas. Am Neurol1994; 36:625-29.

3. Epstein E, Levin D, Croft D, Lutzer M. Mycosis fungoides: survival, prognostic features, response to therapy and autopsy findings.Medicine1972;51:61-72.

4. Hallahan D, Griem M, Griem S, Duda E, Baron J. Mycosis fungoides involving the central nervous system. J Clin Oncol 1986; 4:1638-44.

5. Howlett DC, Malcom PN, Wong WL, Pembakian H, Smith NP, Ayers AB. Case report: symptomatic intracranial involvement bymycosis fungoides. J ClinOncol1995; 7:395-96.

6. Zonenshayn M, Sharma S, Hymes K, Knopp EA, Golfinos JG, Zagzag D. Mycosis fungoidesmetastasizing to the brain parenchyma: case report. Neurosurgery 1998; 42:93337.

7. Chua SL, Seymour JF, Prince HM. Deafness from eighth cranial nerve involvement in a patient with large-cell transformation of mycosis fungoides. Eur $\mathrm{J}$ Haematol2000; 64:340-43.

8. Donovan RC, Freeman C. Brainstem involvement with mycosis fungoides: an unusual central nervous system complication. Am J Neuroradiol2002; 23:533-34.

9. Peris K, Fargnoli MC, Berardelli A, Crecco M, Tomaselli $\mathrm{R}$, Chimenti S. Peripheral nervous system involvement in a patient withlarge T-cell lymphoma arising from a pre-existing mycosis fungoides.Br J Dermatol1998; 139:299-301.

10. Grew JP. Hematologic malignancies. In: Lee GR, ed. Wintrobe's Clinical Hematology. $10^{\text {th }}$ ed. Baltimore, Md: Williams and Wilkins: 1999:2466.

11. Mederos LJ, Jafle ES. Pathology of non-Hodgkin's lymphomas and Hodgkin's disease. In: Wiernik PH, ed. Neoplastic Diseases of the Blood. $3^{\text {rd }}$ ed. New York, NY: Churchill Livingstone; 1995:781. 